JOM, Vol. 67, No. 8, 2015

DOI: $10.1007 / \mathrm{s} 11837-015-1533-2$

(C) 2015 The Minerals, Metals \& Materials Society

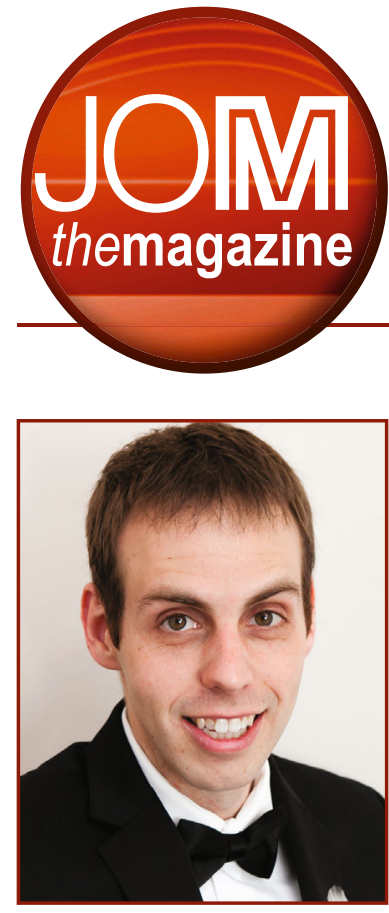

Ben Morrow

\section{About This Article \\ Young Professional \\ Technical Notes is an occasional feature highlighting the scientific interests and professional accomplishments of a young TMS member who has contributed to the technical content of the current issue of JOM as an author, advisor, or guest editor. The development of this feature is a special project of the TMS Young Professionals Committee. For additional information or to find out how you can become involved with JOM, contact Maureen Byko, JOM editor, at mbyko@tms.org.}

\title{
young professional technical notes
}

\section{Ben Morrow Examines Advances in Structural Materials} Kaitlin McMahon

"The challenges posed by structural applications are incredibly interesting," said Ben Morrow, co-author of "A TEM In-Situ Straining Technique to Directly Observe Defects and Interfaces during Deformation in Magnetism," published under the August 2015 JOM technical topic, In-Situ Mechanical Testing in Electron Microscopes: Part I. Morrow points to his educational background at The Ohio State University (OSU), where he earned his bachelor's, master's, and doctorate degrees, as a significant influence on his current research interest in structure-property relationships and the extreme environment of dynamic loading. "My alma mater has always had strong roots in both metallurgy and electron microscopy. I was exposed very early to a diverse range of exciting metallurgical and characterization research," he said.

Connecting the topics discussed in his paper to his work as a staff scientist at Los Alamos National Laboratory (LANL), Morrow notes that the evolution of the microstructure is just as important as the post-mortem of material behavior.

"New in-situ techniques make it possible to directly observe the microstructure of materials during mechanical loading," he said. "With this information, we can clearly see the active deformation mechanisms and how they interact with other microstructural features. We can instantly confirm or deny some of the hypothesized behaviors previously inferred from postmortem studies, and often, completely new, previously unconsidered behaviors become apparent."

New techniques in experimentation, advances in instrumentation, and tools for characterization present important opportunities to the field, according to Morrow. "In the last few years, and certainly continuing into the future, we have seen a tremendous synergy of experimentation and simulation, leading to a rapid acceleration of our understanding of materials," he said. "Large-scale facilities at next-generation light sources hold promise and will offer incredible new tools for materials characterization, especially in-situ testing."

Michael Mills, professor at OSU and 2015 TMS Fellow, served as Morrow's Ph.D. advisor, as well as a technical mentor and professional guide. "He taught me not just about science, but also the role and conduct of great scientists in society," said Morrow.

Several other role models have helped Morrow shape his professional interests, including the three co-authors on his paper-Ellen Cerreta, Rodney McCabe, and Carlos Tomé.

"Each of these people has helped me greatly, and I strive to pay this debt forward to other young scientists in the future." He added that Cerreta, who is deputy group leader at LANL, has "not only served as a constant hero/role model during my time at LANL, but she also first introduced me to the inner workings of TMS, which has been incredibly impactful on my career."

As an active member of various TMS committees, including his current role as vice chair of the Mechanical Behavior of Materials Committee, and a 2014 Young Leaders Professional Development Award recipient, Morrow understands the benefits of early exposure to a professional society. "TMS has been integral to my professional development. I place a high value on the many opportunities to share my research and interact with the scientific community," he said.

Morrow's advice to current students and young scientists and engineers: "Get involved in the scientific community early and often, and strive to be reasonably wellrounded." 